\title{
The Pressure Control Strategy Adjustment of High-Pressure Oil Pipe
}

\author{
Yeping Liang1, Zhezhi Jin ${ }^{2}$ \\ ${ }^{1}$ College of Science, Yanbian University, Yanji, China \\ ${ }^{2}$ College of Economics and Management, Yanbian University, Yanji, China \\ Email: 462613921@qq.com, jinzhezhi@sina.com
}

How to cite this paper: Liang, Y.P. and Jin, Z.Z. (2020) The Pressure Control Strategy Adjustment of High-Pressure Oil Pipe. Open Access Library Journal, 7: e6369. https://doi.org/10.4236/oalib.1106369

Received: April 28, 2020

Accepted: May 15, 2020

Published: May 18, 2020

Copyright (C) 2020 by author(s) and Open Access Library Inc.

This work is licensed under the Creative Commons Attribution International License (CC BY 4.0).

http://creativecommons.org/licenses/by/4.0/

\begin{abstract}
This paper is based on the background of China Undergraduate Mathematical Contest in Modeling Competition A in 2019. Corresponding analysis based on the data given in this question, calculated changes in pressure in the high-pressure tubing according to the different operating conditions for fuel entry and spewing out, in order to determine some operating parameters of the fuel injection system, so as to improve engine efficiency and economic efficiency. The differential equation is constructed by the mass conservation formula under the corresponding conditions, and using MATLAB to implement Runge-Kutta methods to find the numerical solution of the corresponding differential equation.
\end{abstract}

\section{Subject Areas}

Chemical Engineering \& Technology, Fluid Mechanics, Petrochemistry

\section{Keywords}

Mass Conservation, Differential Equation, MATLAB, Runge-Kutta Methods

\section{Introduction}

Since the second industrial revolution, the engine has always been the driving car, aircraft, rockets and a series of large-scale equipment core, so the production and manufacturing technology of engine have been an important indicator of the strength of the manufacturing industry in an industrial modernization country, the study of high efficiency, more stable engine is an important work of national industrial development, which is the most extensive application of fuel engines, the longest development time. Fuel entry and spewing high-pressure tubing are the basis for many fuel engine slots, and the intermittent working 
process of fuel entry and fuel spewing out can cause changes in pressure in the high-pressure tubing [1], which in turn affects the amount of fuel ejected and thus the efficiency of the engine. Therefore, we will establish a model to stabilize the internal pressure of the high-pressure oil pipe by controlling the mechanism of the injectors, so as to achieve low-cost stability of the injection volume and improve the efficiency of engine efficiency [1].

\section{Problem}

In the case of a single nozzle, after a series of basic information such as the size of the inner cavity of a certain type of high-pressure oil pipe, the size of the oil supply intake, the operation of the injector, etc., the model is established to make the pressure in the high-pressure oil pipe as stable as possible by reasonably setting the length of each opening of the check valve. $100 \mathrm{MPa}$ Further adjust the opening time of the unidirectional valve to stabilize it from $100 \mathrm{MPa}$ to $150 \mathrm{MPa}$ after the adjustment process of $2 \mathrm{~s}, 5 \mathrm{~s}$ and $10 \mathrm{~s}$ respectively (Figure 1).

\section{Solution to Problem}

$P_{\text {rail }}$ represents high-pressure oil pump pressure, $P_{\text {int }}$ stands for high-pressure tubpressure pressure, $P_{b a c k}$ stands for injection back pressure, $A_{\text {pipe }}$ stands for intercept area of high-pressure tubing, $L$ stands for pipe length [1].

Using Matlab to fit the data to the curve, in the case of high fitting degree, the function relationship between elastic modulus $E$ and pressure $P$, And because the amount of pressure change in the fuel is proportional to the amount of density change, the scale factor is $\frac{E}{\rho}$, and the differential equations are as follows:

$$
\begin{gathered}
E=f_{e}(p) \\
\mathrm{d} P=\frac{E}{\rho} \mathrm{d} \rho \\
\mathrm{d} P=\frac{f_{e}(p)}{\rho} \mathrm{d} \rho
\end{gathered}
$$

Numerical solution is obtained by using the fourth-order fifth-order Longer-Kuta method, and then the function relationship between density and pressure $P$ is recorded as curve fitting:

$$
\rho=f_{\rho}(p)
$$

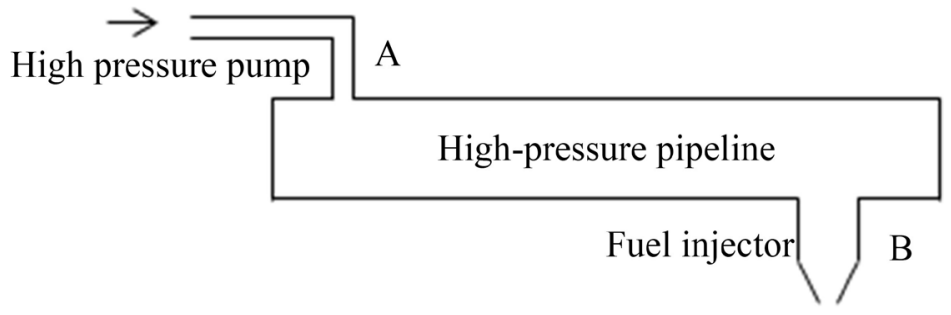

Figure 1. The shape of pump. 
The pressure change in the high-pressure tubing is caused by the change in the density of the fuel in the tube, which can be represented by the one-dimensional mass conservation equation as follows:

$$
m_{\text {in }}^{\prime}-m_{\text {out }}^{\prime}=V \frac{\mathrm{d} \rho}{\mathrm{d} t}[2]
$$

In it, $m_{i n}^{\prime}$ represents the mass flow rate from the high-pressure oil pump to the high-pressure tubing, $m_{\text {out }}^{\prime}$, indicates the mass flow rate of the pipe from the nozzle [3], $V$ represents the volume of the high-pressure tubing, and the flow from the high-pressure oil pump to the high-pressure tubing is

$$
Q=C A \sqrt{\frac{2(160-P)}{\rho_{\text {pumb }}}}[4]
$$

Among them, $Q$ is the amount of fuel per unit of time that flows through the small hole, $C=0.85, A$ is the area for small hole, $\Delta P$ is the pressure difference on both sides of the hole, $\rho$ is the density of fuel on the high-pressure side,

$$
\begin{aligned}
\rho_{\text {pumb }}=f_{\rho}(160)= & 0.8708 \mathrm{mg} / \mathrm{mm}^{3}: \\
m_{\text {in }}^{\prime}= & Q * \rho_{\text {pumb }}=C A \sqrt{2(160-P) \rho_{\text {pumb }}} \\
m_{\text {out }}^{\prime}(t) & =\left\{\begin{array}{lc}
100 \rho t, & 0+100 \mathrm{n} \leq t<0.2+100 \mathrm{n} \\
20 \rho, & 0.2+100 \mathrm{n} \leq t<2.2+100 \mathrm{n} \\
(240-100 t) \rho, & 2.2+100 \mathrm{n} \leq t \leq 2.4+100 \mathrm{n}
\end{array}\right.
\end{aligned}
$$

while $2.4+100 n \leq t \leq 100(n+1), \quad m_{\text {out }}^{\prime}(t)=0$, add the check valve switch function $f_{\text {in }}(t)$

$$
f_{\text {in }}(t)= \begin{cases}1, & n(\Delta t+10) \leq t<n(\Delta t+10)+10 \\ 0, & n(\Delta t+10)+10 \leq t<(n+1)(\Delta t+10)\end{cases}
$$

The derivation of the one-dimensional mass conservation equation is as follows

$$
\begin{gathered}
m_{\text {in }}^{\prime} f_{\text {in }}(t)-m_{\text {out }}^{\prime}=V \frac{\mathrm{d} \rho}{\mathrm{d} t} \\
C A \sqrt{2(160-P) \rho_{\text {pumb }}} f_{\text {in }}(t)-m_{\text {out }}^{\prime}(t)=V \frac{\mathrm{d} \rho}{\mathrm{d} t}
\end{gathered}
$$

Bring it into (4), differential equations of pressure and time in high-pressure tubing are established as follows:

$$
C A \sqrt{2(160-P) f_{\rho}(160)} f_{\text {in }}(t)-m_{\text {out }}^{\prime}(t)=V \frac{\mathrm{d} f_{\rho}(p)}{\mathrm{d} t}
$$

Thus, a model based on the one-dimensional mass conservation equation is established, and the pressure-time curve of the high-pressure oil pipe is obtained under different $t$-cases by the fourth-order, fifth-order Longer-Kuta method [5].

\section{The Solution of the Model}

At first, we can get the formula by fitting the given dates, $E=f_{e}(p)$, the func- 
tion relationship between elastic modulus $E$ and pressure $P$ (Figure $2 \&$ Table 1 )

$$
E=f_{e}(p)=1489 \mathrm{e}^{0.00284 p}+48.79 \mathrm{e}^{0.01376 p}
$$

Then, the differential equation of $P$ and the $p, \mathrm{~d} P=\frac{f_{e}(p)}{\rho} \mathrm{d} \rho$ is using the fourth-order fifth-order [5] Longer-Kuta method to obtain a numerical solution (pressure $P$ from 0 to 200, step 0.1 , a total of 2001 sets of data, special solution to $(0.85,100))$ after the curve fitting to obtain the functional relationship between density and pressure $\rho=f_{\rho}(p)$ the functional relationship between fuel density and pressure $P$ (Figure $3 \&$ Table 2 )

$$
\rho=f_{\rho}(p)=-3.63+4.434 * \cos (0.0005415 p)+0.9645 * \sin (0.0005415 p)(14)
$$

\section{At last, find the best check valve single opening time $\Delta t$}

1) When the pressure stabilization value is $100 \mathrm{MPa}$, the check valve is the single opening time $\Delta t[4]$.

Using the fourth-order, fifth-order Longer-Kula algorithm [2] tries $\Delta t=0.6 \mathrm{~ms}$, The $P$ - $t$ curve obtained by using the one-dimensional mass conservation equation is as follows: (Figure 4)

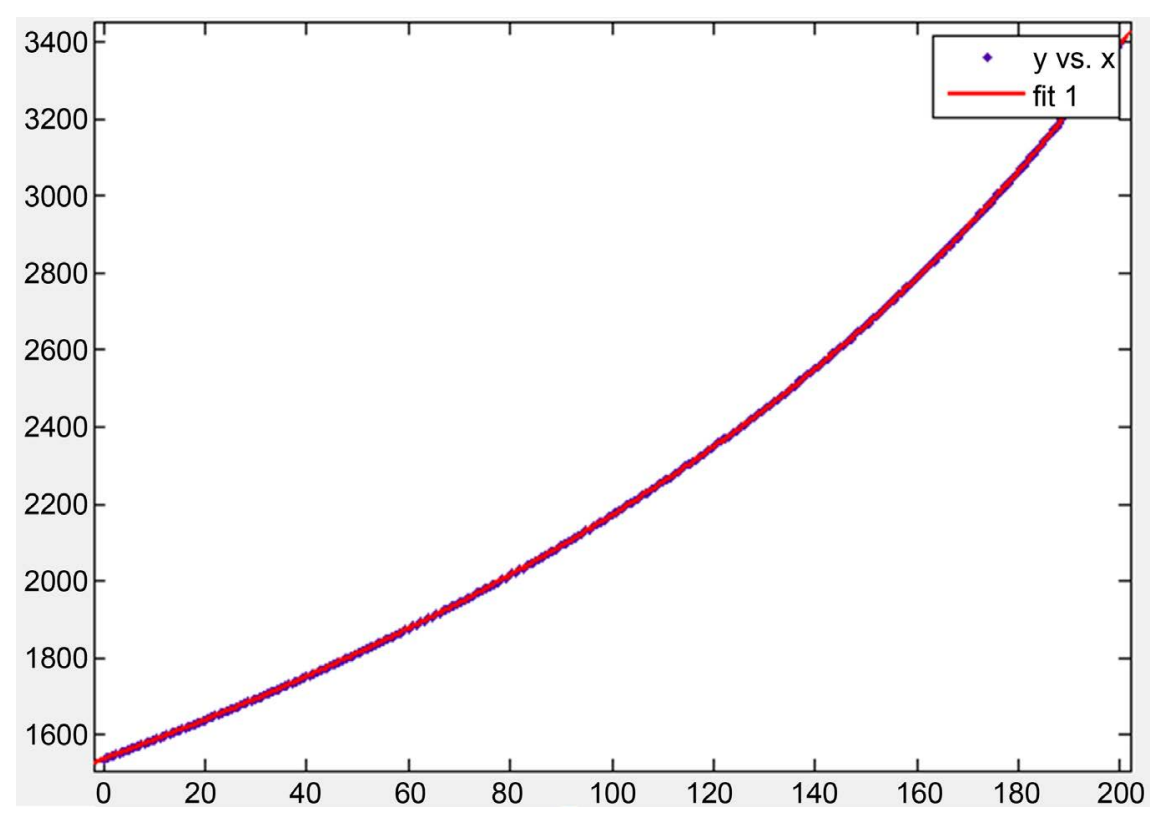

Figure 2. E-P curve.

Table 1. The dates of $E$-P curve.

\begin{tabular}{cccc}
\hline SSE & R-square & Adjusted R-square & RMSE \\
\hline 27.82 & 1 & 1 & 0.2647 \\
\hline
\end{tabular}

Table 2. The dates of $\rho$-P.

\begin{tabular}{cccc}
\hline SSE & R-square & Adjusted R-square & RMSE \\
\hline $1.423 \mathrm{e}-008$ & 1 & 1 & $2.67 \mathrm{e}-006$ \\
\hline
\end{tabular}




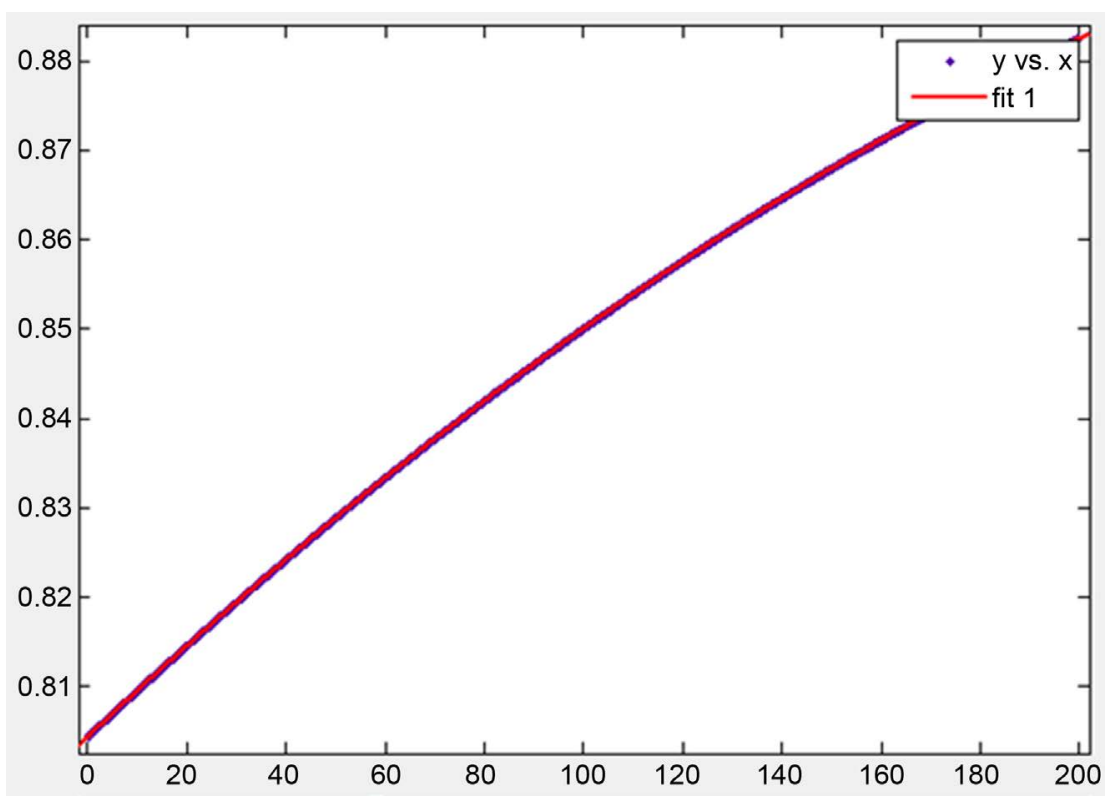

Figure 3. $\rho$ - $P$ curve.

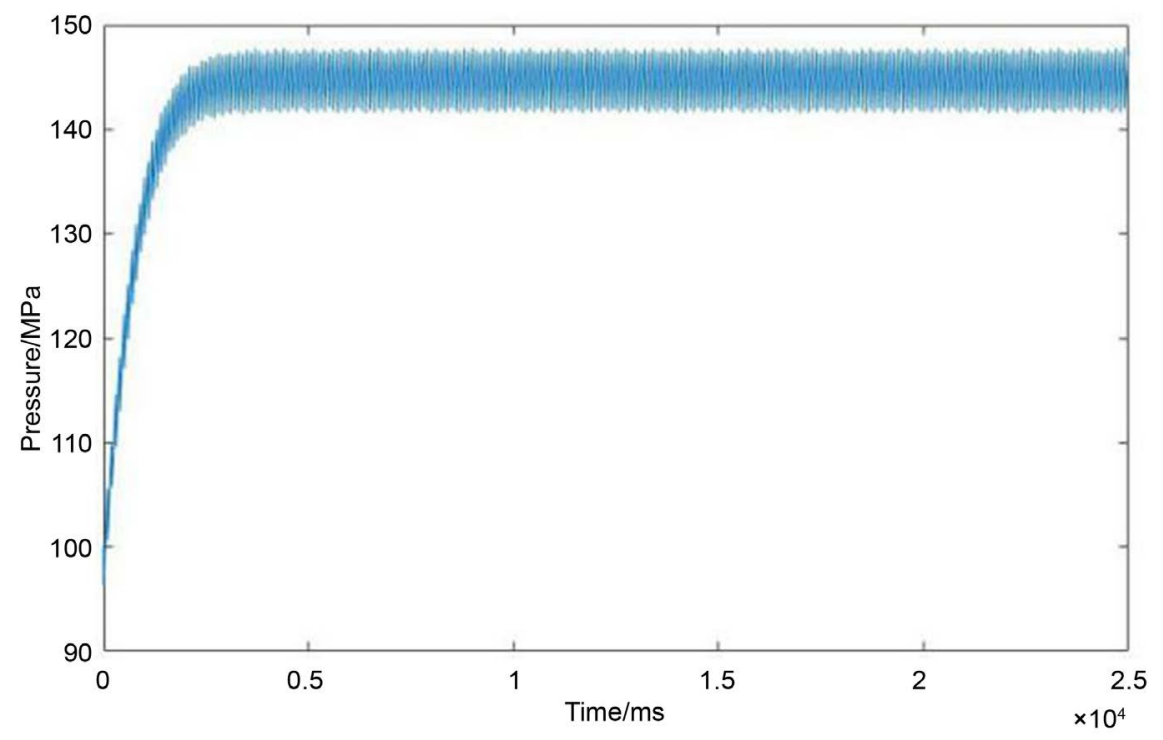

Figure 4. $P$ - $t$ curve.

Analysis of the figure above can be found that when $\Delta t$ fixed, the high-pressure oil pipe in the fuel pressure $P$ will tend to stabilize, but eventually will still fluctuate around a value, thinking, this is a check valve and nozzle work of the cyclical brought about, cannot be avoided. Therefore, this article defines:

$$
\bar{P}=\frac{p_{\min }+P_{\max }}{2}
$$

Stable value $\Delta t$ for pressure in the pipeline in each case, $p_{\min }$ is the minimum value of the fluctuation when the curve tends to stabilize, $P_{\max }$ is the maximum value of the fluctuation when the curve tends to stabilize.

Thus the change curve of $\bar{P}-t$ is as follows: (Figure 5) 
When, $\Delta t=0.289 \mathrm{~ms}, \quad \bar{P}=100 \mathrm{MPa}$

The corresponding $P$ - $t$ curve is as follows: (Figure 6).

2) $\bar{P}=150 \mathrm{MPa}$, the $\Delta t$ adjustment process corresponds to different situations.

As can be seen from the curve in A, $\Delta t=0.755 \mathrm{~ms}, \bar{P}=150 \mathrm{MPa}$, make the $P$ - $t$ curve as follows (Figure 7).

It can be found in the figure that when the check valve is open at $0.755 \mathrm{~ms} \mathrm{a}$ single time, the time required to stabilize from $100 \mathrm{MPa}$ to $150 \mathrm{MPa}$ is $4 \mathrm{~s}$.

a) $\bar{t}=2000 \mathrm{~ms}$ ( $\bar{t}$ indicates the time it takes to move $P$ from $100 \mathrm{MPa}$ to $150 \mathrm{MPa})$.

When the regulation time is $2 \mathrm{~s}$, this paper debugging ideas are as follows: First,

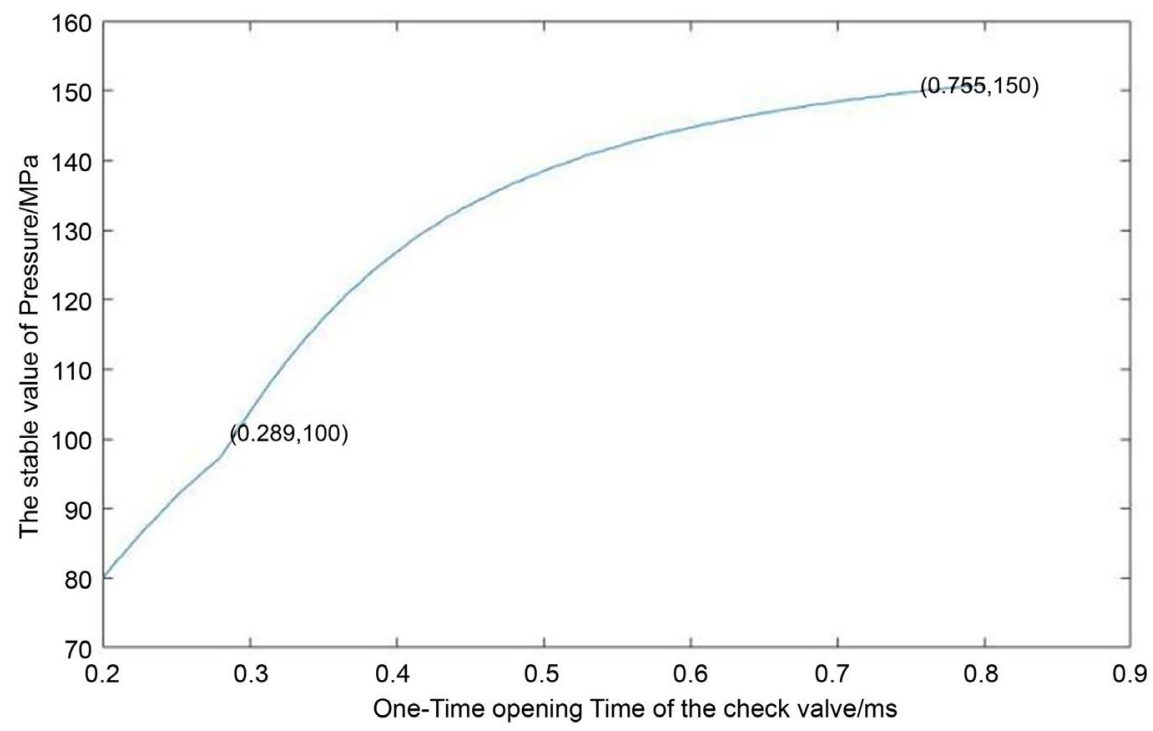

Figure 5. $\bar{P}-\Delta t$ curve.

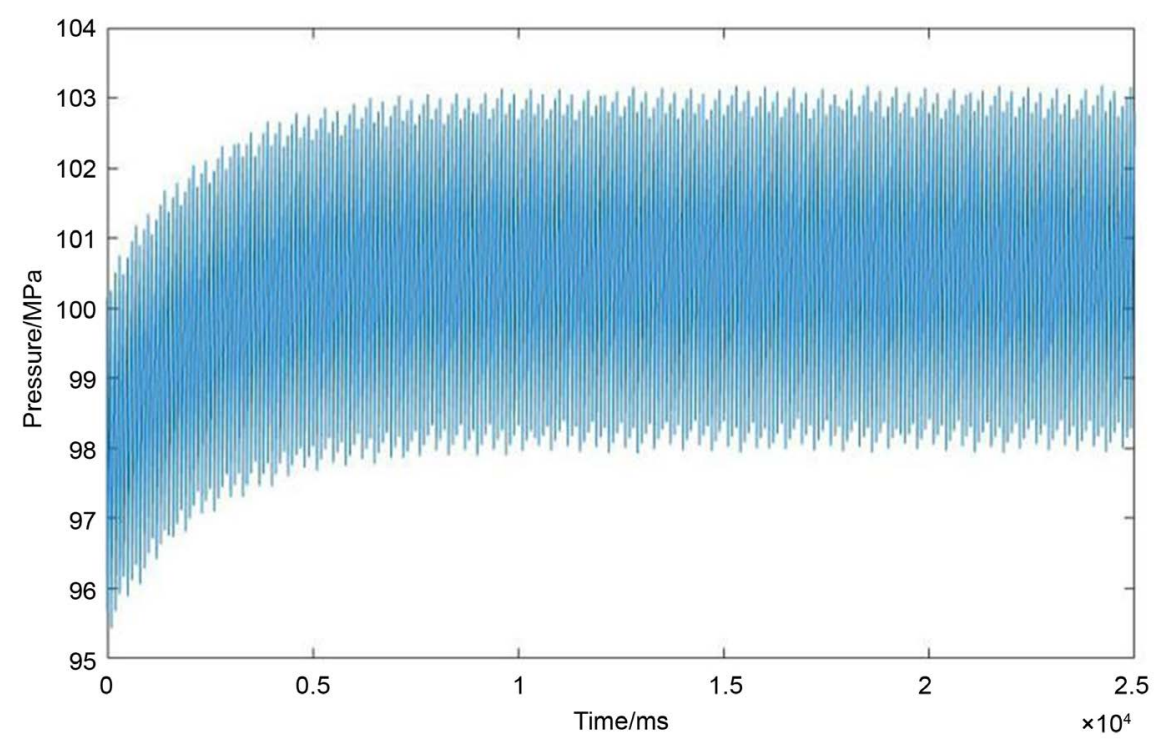

Figure 6. $P$ - $t$ curve $(\Delta t=0.289 \mathrm{~ms})$. 
find the $\Delta t$ value that can use $2 \mathrm{~s}$ to raise $P$ to $150 \mathrm{MPa}$, and then switch $\Delta t$ to 0.755 at $2 \mathrm{~s}$, make $2 \mathrm{~s}$ end of each $\Delta t$ corresponding $P$ - $t$ curve as follows: (Figure $8)$.

When $\Delta t=0.88 \mathrm{~ms}$, you can raise $p$ to $150 \mathrm{MPa}$ at $t=2 \mathrm{~s}$, and then switch $\Delta t$ to $0.755 \mathrm{~ms}$, and make the corresponding $P$ - $t$ graph as follows: (Figure 9).

b) $\bar{t}=5000 \mathrm{~ms}$

Since $5 \mathrm{~s}$ is longer than the time required for $\Delta t=0.755$, the following adjustment ideas can be made

$$
\Delta t=\left\{\begin{array}{l}
0.289 \mathrm{~ms}(\bar{P}=100 \mathrm{MPa}), \quad 0<t \leq \bar{t}-4000 \\
0.755 \mathrm{~ms}(\bar{P}=150 \mathrm{MPa}), \quad \bar{t}-4000<t
\end{array}\right.
$$

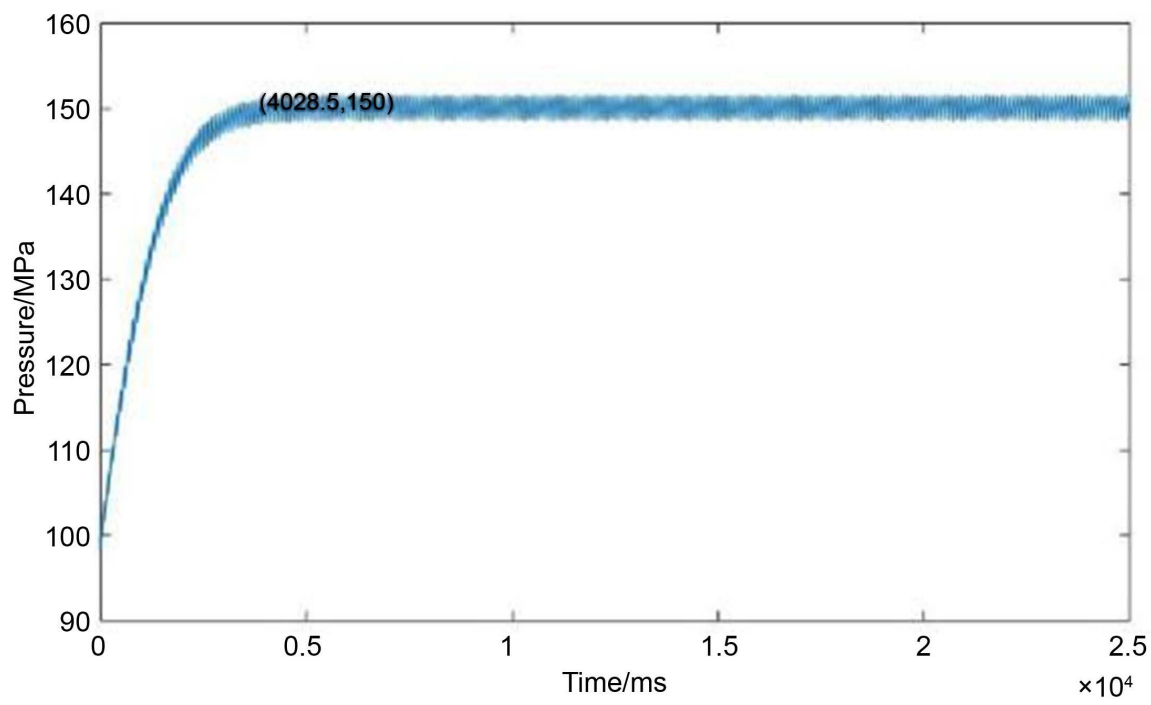

Figure 7. $P$ - $t$ curve $(\Delta t=0.755 \mathrm{~ms})$.

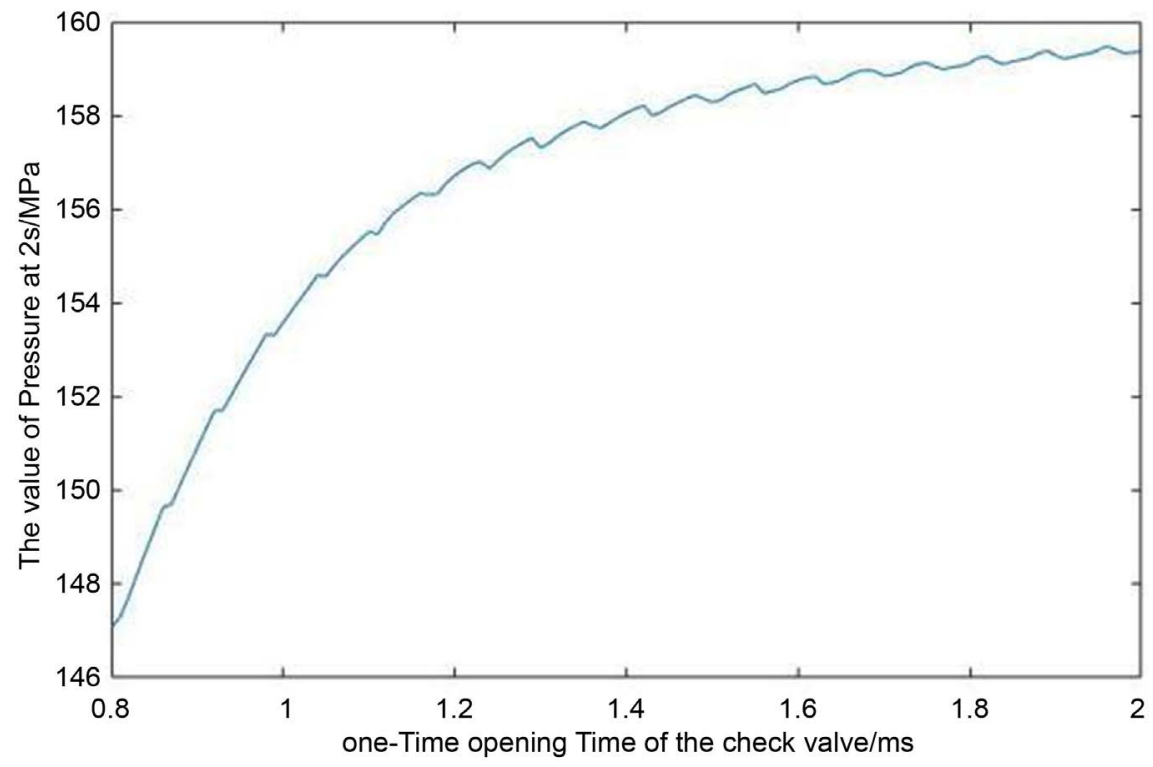

Figure 8. $P$ - $\Delta t$ curve. 
$\bar{t}$ is the time required to stabilize the pressure to $150 \mathrm{MPa}$.

From 0 to $1000 \mathrm{~ms}, \Delta t=0.289 \mathrm{~ms}$, stabilize the tubing pressure $P$ in the 100 $\mathrm{MPa}$, Then the $\Delta t=0.755 \mathrm{~ms}$ can stabilize the $P$ to $150 \mathrm{MPa}$ at the 5 th second.

Make the corresponding $P$ - $t$ curve as follows (Figure 10).

c) $\bar{t}=10000 \mathrm{~ms}$

As the same as the previous text, the first $6000 \mathrm{~ms}$, the check valve single opening time $0.289 \mathrm{~ms}$, the oil pipe pressure $P$ stabilized at $100 \mathrm{MPa}$, and then make $\Delta t=0.755 \mathrm{~ms}$ can be stabilized $P$ in the 10 th second to $150 \mathrm{MPa}$. Make the corresponding $P$ - $t$ curve as follows (Figure 11).

At this point, the problem is solved by the model [1]. The results are as following.

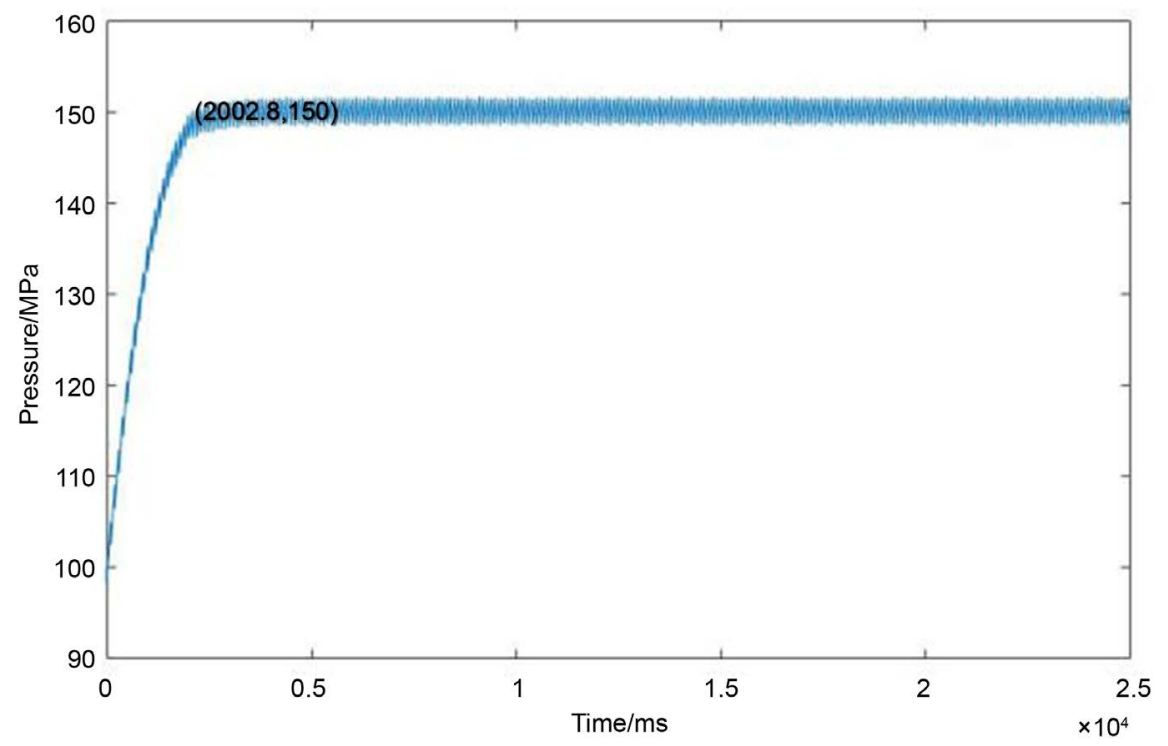

Figure 9. The steady curve at $2 \mathrm{~s}$.

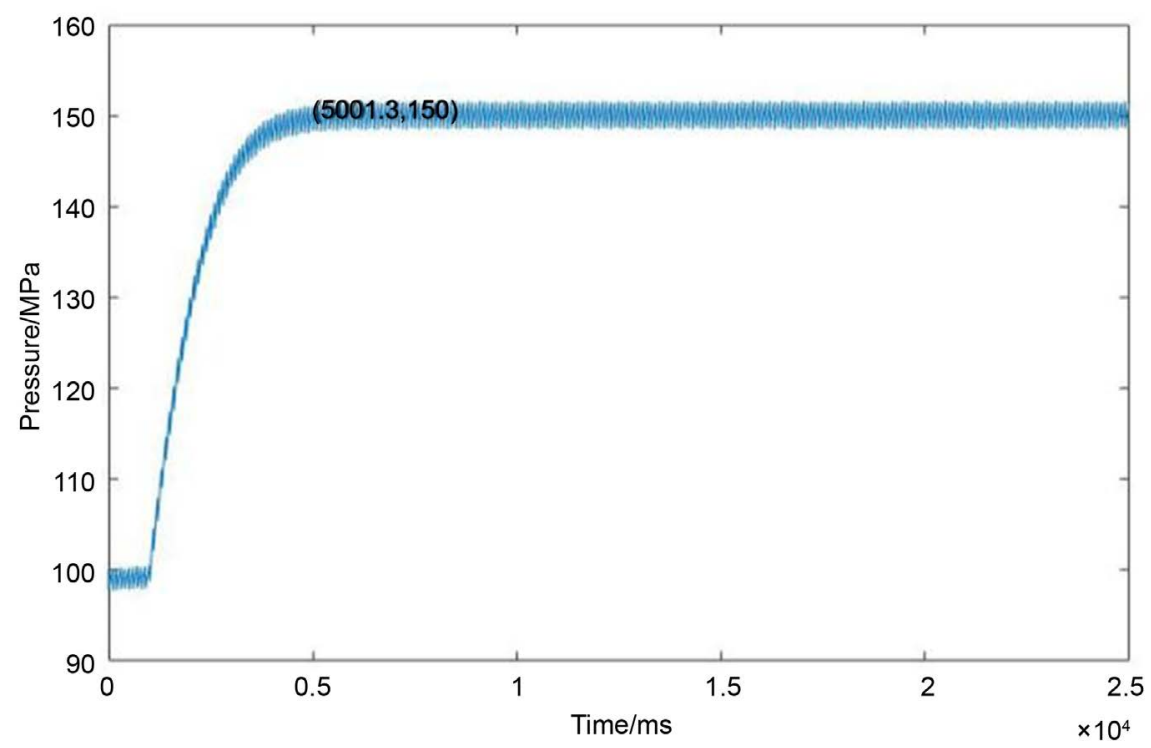

Figure 10. The steady curve at $5 \mathrm{~s}$. 


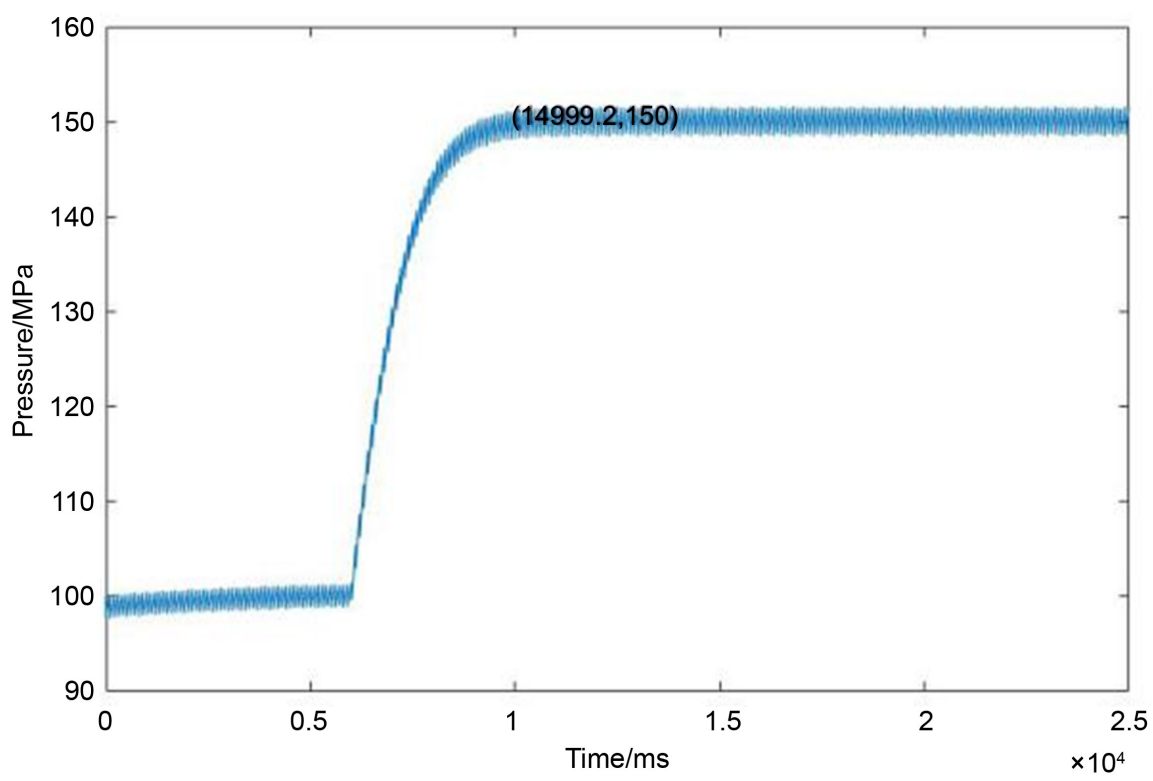

Figure 11. The steady curve at $10 \mathrm{~s}$.

1) Final stabilization, $\bar{P}=100 \mathrm{MPa}$, one-time opening time of the check valve $\Delta t=0.289 \mathrm{~ms}$.

2) Spend $2 \mathrm{~s}$ making $\bar{P}=150 \mathrm{MPa}, 0 \mathrm{~s}-2 \mathrm{~s}, \Delta t=0.88 \mathrm{~ms}, 2 \mathrm{~s}-\infty$, $\Delta t=0.755 \mathrm{~ms}$.

3) Spend $5 \mathrm{~s}$ making the $\bar{P}=150 \mathrm{MPa}, 0 \mathrm{~s}-1 \mathrm{~s}, \Delta t=0.289 \mathrm{~ms}, 2 \mathrm{~s}-\infty$, $\Delta t=0.755 \mathrm{~ms}$.

4) Spend $10 \mathrm{~s}$ making $\bar{P}=150 \mathrm{MPa}, 0 \mathrm{~s}-6 \mathrm{~s}, \Delta t=0.289 \mathrm{~ms}, 2 \mathrm{~s}-\infty$, $\Delta t=0.755 \mathrm{~ms}$.

\section{Conflicts of Interest}

The authors declare no conflicts of interest regarding the publication of this paper.

\section{References}

[1] Zhou, L.B. (2010) Internal Combustion Engines. Machinery Industry Press, Beijing.

[2] Ubertini, S. (2006) Injection Pressure Fluctuations Model Applied to a Multidimensional Code for Diesel Engines Simulation. Journal of Engineering for Gas Turbines and Power, 128, 694-701. https://doi.org/10.1115/1.2135813

[3] Wang, Q.H. (2005) Fluid Dynamics (CFD) Calculation and Experimental Study of 2 Structural Nozzles. Modern Car Power, No. 4, 33-36.

[4] Ding, X.L., Zhang, Y.H. and Xiong, Q.H. (2010) The Characteristics of the Fuel Injection Fluctuation of the Piezoelectric High-Voltage Common Rail Injection System Test. Journal of Agricultural Machinery, No. 7, 11-14.

[5] Yang, Y. (2015) Numerical Solution Seeking Fuzzy Differential Equations by Longekuta Method. Harbin University of Technology, Harbin. 